\title{
Occupational injuries among sewing machine operators in selected garment factories at the Export Processing Zone, Avissawella
}

\section{Eranga Hasarali Kaushalya Fernando ${ }^{1} *$ \& Pushpa Lalani Jayawardana ${ }^{2}$}

${ }^{1}$ Division of Primary Care and Public Health, Brighton and Sussex Medical School, University of Brighton, United Kingdom; ${ }^{2}$ Department of Public Health, Faculty of Medicine, University of Kelaniya, Sri Lanka

*Correspondence: hasaralifernando@gmail.com https://orcid.org/0000-0002-1398-3005

DOI: https://doi.org/10.4038/jccpsl.v27i4.8423

Received on 27 April 2021

Accepted on 17 June 2021

\begin{abstract}
Introduction: Occupational injuries are a major entity on the rise in the whole world. It is necessary to identify the reasons for the injuries to reduce the impact.

Objectives: To determine the incidence, types and associated factors of occupational injuries among sewing machine operators in selected garment factories at the Export Processing Zone, Avissawella, Sri Lanka

Methods: A descriptive cross-sectional study was conducted between August to September 2012, among sewing machine operators in selected garment factories at the Export Processing Zone, Avissawella with one year or more experience in the present factory using a pre-tested self-administered Sinhala questionnaire. Injuries during the last three months were inquired. A sample size of 423 was recruited randomly from four selected factories. The cumulative incidence of injuries for the period was calculated. Associations were tested using chi square test. Bivariate analysis and multiple logistic regression were performed. Results were expressed as odds ratios (OR) and $95 \%$ confidence interval (CI).
\end{abstract}

Results: Response rate was almost $100 \%(\mathrm{~N}=422 / 423)$. Incidence of occupational injuries was 52.1 (95\% $\mathrm{CI}=33.0-77.9)$ per 1000 workers for the three-month period with an estimate of 208.4 (95\% CI=170.7$250.5)$ per 1000 workers per year. The commonest mode of injuries was needle pricks $(n=9 ; 40.9 \%)$. Fingers $(\mathrm{n}=16 ; 72.7 \%)$ were commonly affected resulting in cut injuries or puncture wounds $(\mathrm{n}=8 ; 36.4 \%)$. Male sex $(\mathrm{OR}=2.4 ; 95 \% \mathrm{CI}=1.5-3.3 ; \mathrm{p}=0.049)$ was found to be a risk factor and previous experience in the garment field $(\mathrm{OR}=0.4 ; 95 \% \mathrm{CI}=0.1-0.9 ; \mathrm{p}=0.046)$ was a protective factor.

Conclusions \& Recommendations: The annual cumulative incidence of occupational injuries was observed to be high. Therefore, relevant preventive measures need to be instituted to provide safety of workers. Focus should be on conducting prospective studies.

Keywords: sewing machine operators, occupational injuries, incidence 


\section{Introduction}

Garment industry is the largest single source of export revenue since 1970s in Sri Lanka and accounts for up to $43 \%$ of total export value by late 2000 (1). Workforce of $15 \%$ is involved in textile industries and $85 \%$ of them are females (1). With the rapid growth of textile industry, occupational injuries are a major emerging public health problem.

Occupational injuries are defined as death or personal injury resulting from an occupational accident. The latter is an occurrence arising out of or in the course of work which results in fatal or non-fatal occupational injuries. It is defined as an unexpected and unplanned occurrence, including acts of violence, arising out of or in connection with work, which results in one or more workers incurring a personal injury, disease or death (2). As documented by the World Health Organization (WHO) in 2005, the International Labour Organization (ILO) has reported 268 million non-fatal workplace accidents that resulted in workers missing at least three days of work (3). Nonfatal accidents reported from Asia to the ILO in the year 2014 was $121,256 / 100,000$ persons in the labour force (4) with no classification by the type of occupation or the workers affected. Furthermore, occupational injuries are associated with multiple risk factors which can be both preventable and nonpreventable. Aderaw et al. (2011) reported lack of training $(\mathrm{OR}=1.9 ; 95 \% \mathrm{CI}=1.2-2.9)$, sleep disturbances $(\mathrm{OR}=2.0 ; 95 \% \mathrm{CI}=1.3-3.0)$, job stress $(\mathrm{OR}=2.2 ; 95 \% \mathrm{CI}=1.2-4.4)$ and male sex $(\mathrm{OR}=2.5$; $95 \% \mathrm{CI}=1.6-4.1)$ were significantly associated with occupational injuries (5).

Employers are responsible to provide safe working environment, safe machinery, safe workplace, equipment, and processes. Providing personal protective equipment, informing on measures to deal with emergencies and accidents and providing adequate first aid arrangements are also their responsibilities. Browsing through the literature, scarcity of statistics becomes more than evident. There are no direct comparisons related to sewing machine operators (SMO) and most of the details available are about work related fatal accidents. Given the shortcomings observed regarding the global situation, the state of the Sri Lankan situation regarding occupational injuries needs no special mention. Reporting occupational injuries resulting up to three or more days out of work to the Labour Department is a requirement under the Factory's Ordinance No. 45 of 1942 (6). However, according to officials this is not strictly adhered to.

A study done at the Free Trade Zone, Koggala (7) in the Southern Province, had reported that $63.7 \%$ of females work as sewing machine operators. Six percent $(5.6 \%)$ of them had experienced a recent workplace injury (period not defined), of which $68.3 \%$ were due to puncture wounds. Another Sri Lankan study done on the effect of human factors in causation of accidents reported $32 \%$ of the accidents occurring in the textile industry (8). Therefore, this study was done to determine the incidence, types and associated factors of occupational injuries among SMOs in selected garment factories at the Export Processing Zone, Avissawella, Sri Lanka.

\section{Methods}

A descriptive study was carried out in four garment factories at Avissawella, which is one such major Export Processing Zones, where 13 garment factories are in operation. The study had to be confined to the four selected garment factories for which permission was granted by the management to carry out the research, which denied the principal investigator of the opportunity to select the factories using a probability sampling method. It was done from August to September 2012. The production of factories has a seasonal variability depending on the demand to the product. According to the higher officials, their higher production period is usually from May to November, and it fitted well with the data collection period made available.

Sewing machine operators in those garment factories were considered as the reference population and an SMO with equal or more than one year of experience in the present garment factory was taken as the study unit. Those unable to read and write Sinhala language were excluded. The sample size was calculated applying the formula for calculation of incidence rate 
(9) and was calculated at $95 \%$ significance level, with a relative precision taken as $10 \%$ and a non-response rate considered as $10 \%$, the calculated sample size was 422 .

A total sample of 423 out of 1354 workers was selected from the factories applying probabilityproportionate-to-size (PPS) of the SMOs in each factory. The number required from individual factory was based on simple random sampling. The names of eligible SMOs who reported to work on the day of the study were taken from the factory. A list was arranged in the alphabetical order and numbers were assigned in ascending order. The study units were selected from this list corresponding to a computer-generated random number.

A pretested, self-administered anonymous questionnaire in Sinhala was used to collect primary data related to the socio-demographic characteristics, occupational injury, and the putative risk/protective factors. The period of enquiry related to injuries was confined to three months to minimize recall errors, since a longer period of recall of self-reported injuries can result in gross under-reporting and underestimation (10-13). Since outsiders had no access to the surveillance or the medical records, there was no way to cross check the authenticity of self-reported injuries. The data were collected by the principal investigator. In each factory, the whole process took over three days to complete.

Statistical analysis was performed using the Statistical Package for Social Sciences (SPSS) version 14 and WINPEPI version 11.26. Any injury resulting during work at the workplace was considered as an occupational injury. An SMO who had sustained one or more injuries during the reference period of three months was considered as an outcome. Cumulative incidence of injuries for this period with the relevant $95 \% \mathrm{CI}$ was computed under descriptive statistics. Associated factors were analysed using bivariate analysis. All variables were handled as qualitative variables and Pearson's Chisquare test with Yates's correction was used to test for associations. Multivariate logistic regression analysis was conducted to control the effect of confounding. A probability level ( $p$ value) of $<0.05$ was considered as having a significant association. The associations were expressed using OR and 95\% CI, which were based on Fisher's Exact Method.

\section{Results}

Of the 423 SMOs selected, one subject did not respond giving a response rate of almost $100 \%$. They were in the range of 17 to 54 years with a mean age of 26.4 years $(S D=6)$. Seventy five percent $(n=317)$ of them consisted of females and 56\% ( $\mathrm{n}=234)$ were unmarried. All of them have had some formal education and the majority $(\mathrm{n}=235 ; 56 \%)$ had received secondary education. A minority $(\mathrm{n}=165$; $39 \%$ ) has passed General Certificate of Education (GCE) Advanced Level (A/Level) with only 14 (3\%) who have undergone tertiary education. Majority $(\mathrm{n}=213 ; 51 \%)$ claimed to have previous experience in the garment field before joining the current factory. Education on injury prevention has been received by $82 \%(n=345)$ and the majority $(n=234 ; 55 \%)$ claimed to have training on first aid. Personal protective equipment was used by $81 \%(n=343)$ of them at present. Ninety four percent $(\mathrm{n}=398)$ of the workers reported adequate light; $86 \%(\mathrm{n}=361)$ tolerable background noise; and $84 \%(\mathrm{n}=353)$ tolerable heat in the working environment. However, a majority $(\mathrm{n}=383 ; 91 \%)$ of SMOs claimed to experience varying degrees of sweating during work.

\section{Incidence of occupational injuries}

The total number of SMOs who have sustained any type of occupational injury during the three months prior to the survey was 22 . Thus, the cumulative incidence of occupational injuries for a period of three months was $52(95 \% \mathrm{CI}=33.0-77.9)$ per 1000 garment factory workers in the study population. Thus, the estimated annual cumulative incidence is expected to be 208 per 1000 garment factory SMOs (95\% CI=170.7-250.5). A higher incidence of injuries was reported in the 36-45 year age group (129 per 1000 population) and in males (95 per 1000 population) during the three months prior to the survey. The commonest injuries $(\mathrm{n}=9 ; 41 \%)$ among SMOs were due to needle pricks. Fingers $(n=16$; 
$73 \%$ ) were the major site of injury. Equal number of cut injuries and puncture wounds $(n=8 ; 36 \%)$ were reported.

\section{Factors associated with sustaining occupational injuries}

As shown in Table 2, male SMOs in comparison to females $(O R=2.7 ; 95 \% \mathrm{CI}=1.2-6.1 ; \mathrm{p}<0.05)$ and ever married SMOs in comparison to unmarried both had an increased risk $(\mathrm{OR}=2.8 ; 95 \% \mathrm{CI}=1.1-8.3 ; \mathrm{p}<0.05)$ of sustaining injuries. There was no significant association between occurrence of occupational injuries and age categories of 36-55 versus 16-35 years $(\mathrm{OR}=2.4 ; 95 \% \mathrm{CI}=0.6-7.8 ; \mathrm{p}>0.05)$ and those with an education level above GCE Ordinary Level $(\mathrm{O} / \mathrm{L})$ versus those educated up to $\mathrm{GCE} \mathrm{O} / \mathrm{L}$ $(\mathrm{OR}=1.4 ; 95 \% \mathrm{CI}=0.5-3.6 ; \mathrm{p}>0.05)$. Those SMOs who had previous experience in the garment field in comparison to those who lacked experience had an increased risk $(\mathrm{OR}=3.5,95 \% \mathrm{CI}=1.2-12.5 ; \mathrm{p}<0.05)$ of sustaining injuries.

There were no significant associations between occurrence of occupational injuries and occupation related factors such as permanent versus casual status $(\mathrm{OR}=1.2 ; 95 \% \mathrm{CI}=0.4-6.7 ; \mathrm{p}>0.05)$, full time versus part time basis at work $(\mathrm{OR}=1.0 ; 95 \% \mathrm{CI}=0.4-6.7$; $\mathrm{p}>0.05)$, job related occupational training versus no training $(\mathrm{OR}=2.6 ; 95 \% \mathrm{CI}=0.4-109.7 ; \mathrm{p}>0.05)$ and use versus non-use of personal protective equipment $(\mathrm{OR}=1.3 ; 95 \% \mathrm{CI}=0.4-3.8 ; \mathrm{p}>0.05)$.

With reference to the work environment (Table 3), there were no significant association between occupational injuries and over-lit/inadequate light versus adequacy of light $(\mathrm{OR}=1.01 ; 95 \% \mathrm{CI}=0.02$ $7.05 ; \mathrm{p}>0.05)$, very noisy versus tolerable noise/not noisy $(\mathrm{OR}=2.8 ; 95 \% \mathrm{CI}=0.6-9.4 ; \mathrm{p}>0.05)$, excess heat/cold versus tolerable heat $(\mathrm{OR}=1.3 ; 95 \%$ $\mathrm{CI}=0.3-4.0 ; \mathrm{p}>0.05)$ and sweating versus no sweating $(\mathrm{OR}=1.02 ; 95 \% \mathrm{CI}=0.2-9.3 ; \mathrm{p}>0.05)$.

Of the socio-demographic factors, occupation related factors and stress, only two factors became significant at the multivariate analysis. Those included males in comparison to female SMOs having an increased risk $(\mathrm{OR}=2.4 ; 95 \% \mathrm{CI}=1.5-3.3$; $\mathrm{p}<0.05)$ and having prior experience in the garment field in comparison to lack of experience $(\mathrm{OR}=0.4$; $95 \% \mathrm{CI}=0.1-0.9 ; \mathrm{p}<0.05)$ as having a reduced risk.

Table 1: Age and sex specific incidence of injuries among sewing machine operators during the past three months

\begin{tabular}{lrrrr}
\hline \multirow{2}{*}{ Demographic factors } & \multicolumn{2}{c}{ Sustained injury } & $\begin{array}{c}\text { Incidence/1000 } \\
\text { population }\end{array}$ & 95\% CI \\
\hline Age (years) & Yes $(\mathbf{n}=\mathbf{2 2})$ & No (n=400) & & \\
$16-25$ & $6(27 \%)$ & $215(54 \%)$ & 27.2 & $10.0-58.2$ \\
$26-35$ & $12(54 \%)$ & $152(38 \%)$ & 73.2 & $38.4-124.3$ \\
$36-45$ & $4(18 \%)$ & $27(7 \%)$ & 129.0 & $36.3-298.3$ \\
$46-55$ & $0(0 \%)$ & $6(2 \%)$ & 0.0 & - \\
\hline Sex & & & & \\
Male & $10(45 \%)$ & $95(24 \%)$ & 95.2 & $46.6-168.2$ \\
Female & $12(55 \%)$ & $305(76 \%)$ & 37.9 & $19.7-65.2$ \\
\hline
\end{tabular}


Table 2: Socio-demographic and occupational factors associated with occupational injuries in the bivariate analysis

\begin{tabular}{|c|c|c|c|}
\hline \multirow{2}{*}{ Socio-demographic factors } & \multicolumn{2}{|c|}{ Incidence of injuries during past 3 months } & \multirow{2}{*}{$\begin{array}{c}\text { Significance } \\
\text { OR }(95 \% \mathrm{CI})\end{array}$} \\
\hline & Yes $(n=22)$ & No $(n=400)$ & \\
\hline Age in years & & & $\chi^{2}=1.4 ; \mathrm{df}=1$ \\
\hline $36-55$ & $4(18 \%)$ & $34(08 \%)$ & $\mathrm{p}>0.05$ \\
\hline $16-35$ & $18(82 \%)$ & $366(92 \%)$ & $2.4(0.6-7.8)$ \\
\hline Sex & & & $\chi^{2}=4.2 ; \mathrm{df}=1$ \\
\hline Male & $10(45 \%)$ & $95(24 \%)$ & $\mathrm{p}<0.05$ \\
\hline Female & $12(55 \%)$ & $305(76 \%)$ & $2.7(1.2-6.1)$ \\
\hline Civil status & & & $\chi^{2}=4.3 ; \mathrm{df}=1$ \\
\hline Ever married* & $15(68 \%)$ & $173(43 \%)$ & $\mathrm{p}<0.05$ \\
\hline Unmarried & $7(32 \%)$ & $227(57 \%)$ & $2.8(1.1-8.3)$ \\
\hline Educational level & & & $\chi^{2}=0.3 ; \mathrm{df}=1$ \\
\hline Above $\mathrm{O} / \mathrm{L}$ & $11(50 \%)$ & $168(42 \%)$ & $\mathrm{p}>0.05$ \\
\hline $\mathrm{Up}$ to $\mathrm{O} / \mathrm{L}$ & $11(50 \%)$ & $232(58 \%)$ & $1.4(0.5-3.6)$ \\
\hline Employment status & & & $\chi^{2}=0.001 ; \mathrm{df}=1$ \\
\hline Permanent & $19(86 \%)$ & $335(84 \%)$ & $p>0.05$ \\
\hline Casual & $3(14 \%)$ & $65(16 \%)$ & $1.2(0.4-6.7)$ \\
\hline Full/ part time basis & & & $\chi^{2}=0.0 ; \mathrm{df}=1$ \\
\hline Full time & $15(68 \%)$ & $271(68 \%)$ & $\mathrm{p}>0.05$ \\
\hline Part time & $7(32 \%)$ & $129(32 \%)$ & $1.02(0.4-3.0)$ \\
\hline Occupational training & & & $\chi^{2}=3.6 ; \mathrm{df}=1$ \\
\hline Received & $21(95 \%)$ & $356(89 \%)$ & $\mathrm{p}>0.05$ \\
\hline Not received & $1(05 \%)$ & $44(11 \%)$ & $2.6(0.4-109.7)$ \\
\hline Prior experience in garment field & & & $\chi^{2}=5.6 ; \mathrm{df}=1$ \\
\hline Yes & $17(77 \%)$ & $196(49 \%)$ & $\mathrm{p}<0.05$ \\
\hline No & $5(23 \%)$ & $204(51 \%)$ & $3.5(1.2-12.5)$ \\
\hline Personal protective equipment & & & $\chi^{2}=0.05 ; \mathrm{df}=1$ \\
\hline Used & $5(23 \%)$ & $74(18 \%)$ & $\mathrm{p}>0.05$ \\
\hline Not used & $17(77 \%)$ & $326(82 \%)$ & $1.3(0.4-3.8)$ \\
\hline
\end{tabular}

$\mathrm{OR}=$ odds ratio; $95 \% \mathrm{CI}$ : 95\% confidence interval; $\mathrm{df}=$ degrees of freedom 
Table 3: Environmental conditions associated with occupational injuries in the bivariate analysis

\begin{tabular}{|c|c|c|c|}
\hline \multirow{2}{*}{ Socio-demographic factors } & \multicolumn{2}{|c|}{ Incidence of injuries during past 3 months } & \multirow{2}{*}{$\begin{array}{c}\text { Significance } \\
\text { OR }(95 \% \text { CI })\end{array}$} \\
\hline & Yes $(n=22)$ & No $(n=400)$ & \\
\hline Light & & & $\chi^{2}=0.0 ; \mathrm{df}=1$ \\
\hline Over lit/ inadequate** & $1(5 \%)$ & $18(4 \%)$ & $\mathrm{p}>0.05$ \\
\hline Adequate/ do not know\# & $21(95 \%)$ & $382(96 \%)$ & $1.01(0.02-7.1)$ \\
\hline Noise & & & $\chi^{2}=2.1 ; \mathrm{df}=1$ \\
\hline Very noisy & $4(18 \%)$ & $29(07 \%)$ & $\mathrm{p}>0.05$ \\
\hline Tolerable/ not noisy** & $18(82 \%)$ & $71(93 \%)$ & $2.8(0.6-9.4)$ \\
\hline Heat & & & $\chi^{2}=0.01 ; \mathrm{df}=1$ \\
\hline Excess heat/ cold** & $4(18 \%)$ & $60(15 \%)$ & $\mathrm{p}>0.05$ \\
\hline Tolerable/ do not know\# & $18(81 \%)$ & $340(85 \%)$ & $1.3(0.3-4.0)$ \\
\hline Sweating & & & $\chi^{2}=0.0 ; \mathrm{df}=1$ \\
\hline Always/most times** & $20(91 \%)$ & $363(91 \%)$ & $\mathrm{p}>0.05$ \\
\hline Never & $2(9 \%)$ & $37(9 \%)$ & $1.02(0.2-9.3)$ \\
\hline
\end{tabular}

$\mathrm{OR}=$ odds ratio; $95 \% \mathrm{CI}=95 \%$ confidence interval; $\mathrm{df}=$ degrees of freedom

*Ever married include married, divorced and widowed workers

** \& \#: indicates the levels pooled for the $2 \times 2$ analysis

\section{Discussion}

The incidence of occupational injuries among SMOs for the period of three months preceding the survey was 52.1 per 1000 workers, with an estimated annual figure of 208 per 1000 SMOs. The commonest types of injuries were puncture wounds and cut injuries. Being a male (risk factor) and experience in the garment field (protective factor) were the associated factors identified.

The incidence reported is considered an underestimate due to several reasons which is one limitation of the study. Latter being of retrospective nature, there could have been recall errors, with a high probability that extremely minor injuries would have been missed leading to an underestimate, despite the reference period was as short as three months. Since there was no access to the records maintained to crosscheck, the investigator had to rely only on self-reports which is another limitation. A shorter reference period than three months may enhance provision of more accurate estimates (10), but with relatively low number of outcome events.
Therefore, it needs to strike a balance between the reference period and the latter. According to the literature, the ability to recall increased with the severity of the injury (11). However, in the present study, only minor injuries were reported (which are unlikely to be registered in memory) further increasing the likelihood of recall errors. No information was obtainable from the management regarding the absentees, and this would have contributed further to an underestimate of incidence, had their absence being due to occupational injuries. With reference to labour turnover, it was possible only to assess the survivors in the industry and not those who would have left the industry due to major/repeated accidents owing to the nature of the study design. Further, the research had to be conducted as a descriptive study due to logistical and administrative reasons. Even though conducting a prospective follow up study was a better option to counteract the above issues, due to the constraints imposed by the management, it was not a viable option. This is considered as another limitation of the study. Therefore, future research should focus on this aspect. 
Although the four garment factories were selected purposively due to issues related to obtaining permission, the SMOs were selected randomly applying PPS to the total number of workers in each factory. This is considered a strength of the study which enhances the generalizability of the results equally to all the four factories.

Based on the results of this study, the human factors identified were male sex (risk factor) and prior experience in the garment sector (protective factor). The known protective factors such as training on injury prevention, educational level and use of personal protective equipment (PPE) did not reach statistical significance which may be attributed to inadequate numbers related to the outcome event. Jaiswal et al. (14) however had reported education as a measure of injury prevention. The direction of the OR regarding the above factors are implausible. It has been stated that education alone cannot prevent injuries when there are more hazards in the working environment and less safety in the industries (5) and this applies to both being trained on injury prevention and availability of PPE as well.

No association was found with age and injuries in the study reported by Badathurage et al. (8) in Sri Lanka nor the present study. Contrary to above Jaiswal (14) reported that the younger age $(<30$ year) had a significantly higher risk. Consistent with the present study, a significant association between incidence of injuries and male sex was observed by Jaiswal et al. (14) and Aderaw et al. (5) However, Badathurage (8) had reported that there was no association between sustaining injuries and sex. Mohammadfam \& Moghimbeigi (15) had found a statistically significant association between being married and sustaining occupational injuries $(\mathrm{OR}=4.7 ; 95 \%$ $\mathrm{CI}=1.9-11.7 ; \mathrm{p}=0.001)$ in Iran. On the contrary, Nakata et al. (16) reported that unmarried workers were more at odds of becoming injured $(\mathrm{OR}=1.4$; $95 \% \mathrm{CI}=1.1-1.8 ; \mathrm{p}=0.01)$. In the present study, although marital status was significant in the bivariate analysis, it failed to reach statistical significance in the multivariate analysis which controlled for confounding effects. These observations indicate inconsistency between the findings of reported studies from different countries.

As the injuries related to SMOs were mainly of minor severity, the temporary absences from work may not exceed three days, with a minimum being a single day in most instances. However, the disease burden could become substantial if and when infection and other complications sets in, leading to several days lost resulting from temporary incapacity. This is likely to create an economic loss to the industry in terms of loss of production and the need to bear medical costs. Based on the ILO and the studies and estimates computed by many countries, it has set forth that economic costs of work-related illness and injury vary from $1.8-6 \%$ of GDP with an average of $4 \%$ (17). Considering these facts, it is imperative that preventive measures are adopted to protect the workers. It is also important to revisit the training programmes and revise those by providing hands on training especially for those who do not have prior experience. Further, this situation may be improved by having close supervision. It is also important to get the management to establish a surveillance system, if not available still, and maintain a detailed record of the injuries that occur, including the mechanism of the injury and what preventive measures were in use at the time of the injury.

\section{Conclusions \& Recommendations}

In conclusion, the annual cumulative incidence of occupational injuries among SMOs was observed to be high $(20 \%)$ even though minor in severity, and therefore the relevant preventive measures need to be instituted to provide safety of workers and to reduce the economic losses. 


\section{Public Health Implications}

- The importance of establishing a proper injury surveillance system (in its absence) to report even minor injuries is emphasized as it is a legal requirement to maintain statistics for the benefit of the future prevention programmes.

- It needs to revisit and revise the training programmes focusing on improvement of capacity and use of safe practices at work correctly and constantly; and make it a responsibility of the employees with strict supervision.

- Focus should be on prospective longitudinal studies which enable compilation of accurate data and identifying factors leading to labour turnover and disabling and fatal injuries that may occur.

\section{Author Declarations}

Competing interests: Authors declare that there is no conflict of interest.

Ethics approval and consent to participate: Ethical clearance for the study was obtained from the Ethics Review Committee of the Faculty of Medicine, Colombo, Sri Lanka (EC-12-069).

Funding: No external funding involved

Author contributions: EHKF: Developing the study proper, data collection, analysis and preparation of the manuscript of the study. PLJ: Designing the study, reviewing the manuscript, revising it substantially and planning the data analysis.

\section{References}

1. En Wikipedia. Apparel industry of Sri Lanka. Wikipedia, 10 September 2012. Available from: https://en.wikipedia.org/w/index.php?title=Appar el_industry_of_Sri_Lanka\&oldid=987817953.

2. Laborsta. Occupational injuries. Laborsta, 25 September 2012. Available from: http://aborsta. ilo.org/default.html.

3. World Health Organization. Number of workrelated accidents and illnesses continues to increase, WHO, 12 November 2012. Available from: http://www.who.int/mediacentre/news/ releases/2005/pr18/en/index.html.

4. Hamalainen P, Takala J, Kiat T. Global Estimates of Occupational Accidents and Work-Related Illnesses 2017. Singapore, 2017. Available from: http://www.icohweb.org/site/images/news/pdf/Re port $\% 20$ Global $\% 20$ Estimates $\% 20$ of $\% 20$ Occupati onal $\% 20$ Accidents $\% 20$ and $\% 20$ Workrelated\%20Illnesses\%202017\%20rev1.pdf.

5. Aderaw Z, Engdaw D, Tadesse T. Determinants of occupational injury: A case control study among textile factory workers in Amhara Regional State, Ethiopia. J Trop Med 2011: 1-8. DOI:10.1155/ 2011/657275.

6. Labour Department. The Factory Ordinance, No.45 Of 1942. Labourdept, 1974. Available from:

http://labourdept.gov.lk/images/PDF_upload/chap ter04/2_factories_ordinance_ii.pdf.

7. De Silva V, Lipscomb H, Ostbye T. Occupational health problems among female garment factory workers in Sri Lanka. Occup Environ Med 2011; 68(1): A127-A127. DOI: 10.1136/oemed-2011100382.422 .

8. Badathurage M. Analysis of the current state of occupational hazard control and risk management in garment industry (Unpublished manuscript). Open University of Sri Lanka, 2009.

9. Lwanga SK \& Lemeshow S. Sample Size Determination in Health Studies: A Practical Manual. Geneva: World Health Organization, 1991. Available from: https://apps.who.int/iris/ handle/10665/40062

10. Landen D \& Hendricks S. Effect of recall on reporting of at-work injuries. Public Health Rep 1997; 110(3): 350-354. DOI: 10.1016/s00224375(97)90342-x.

11. Zwerling C, Sprince N, Wallace R, Davis C, Whitten $\mathrm{P}$, Heeringa S. Effect of recall period on the reporting of occupational injuries among older workers in the health and retirement study. Am J Ind Med 199; 28(5): 583-590. DOI: 10.1002/ajim.4700280503.

12. Mock C, Acheampong F, Adjei S, Koepsell T. The effect of recall on estimation of incidence rates for injury in Ghana. Int J Epidemiol 1999; 28(4): 750-755. DOI: 10.1093/ije/28.4.750. 
13. Moshiro C, Heuch I, Astrom A, Setel P, Kvale G. Effect of recall on estimation of non-fatal injury rates: a community-based study in Tanzania. Inj Prev 2005; 11(1): 48-52. DOI: 10.1136/ip.2004. 005645.

14. Jaiswal A. A case control study among carpet thread factory workers in Uttar Pradesh, India: occupational injury and its deteriorating factors. Glob J Hum Soc Sci 2012; 10(12). Available from: https://globaljournals.org/.../3-A- CaseControl-Study-Among-Carpet.pdf.

15. Mohammadfam I, Moghimbeigi A. Evaluation of injuries among a manufacturing industry staff in Iran. J Res Health Sci 2009; 9(1): 7-12. Available from: https://www.researchgate.net/publication/
235366834_Evaluation_of_Injuries_among_a_M anufacturing_Industry_Staff_in_Iran

16. Nakata A, Ikeda T, Takahashi M, Haratani T, Hojou M Swanson NG, Fujioka Y, Araki S. The prevalence and correlates of occupational injuries in small scale manufacturing enterprises. J Occup Health 2006; 48(5): 366-376. Available from: https://www.jstage.jst.go.jp/article/joh/48/5/48_5 366/_pdf.

17. Takala J, Saarela K, Yun L, Manickam K, Jin T, Heng P, et al. Global Estimates of the Burden of Injury and Illness at Work in 2012. J Occup Environ Hyg 2014; 11(5): 326-337. DOI:10.1080/154596 24.2013.863131. 